\title{
Desenvolvimento larval de Paratanaisia bragai (Santos) (Digenea, Eucotylidae) sob condições experimentais
}

\author{
Solange V. P. B. Brandolini ${ }^{1} \&$ Suzana B. Amato ${ }^{2}$
}

\author{
${ }^{1}$ Departamento de Biologia Animal, Universidade Federal Rural do Rio de Janeiro. Caixa postal 74555, 23851-970 \\ Seropédica, Rio de Janeiro, Brasil. E-mail: solangeb@ufrrj.br \\ ${ }^{2}$ Departamento de Zoologia, Universidade Federal do Rio Grande do Sul. Caixa postal 15014, 91501-970 Porto Alegre, \\ Rio Grande do Sul, Brasil. E-mail: sbamato@ufrgs.br
}

\begin{abstract}
Larval development of Paratanaisia bragai (Santos) (Digenea, Eucotylidae) under experimental conditions. The larval development of Paratanaisia bragai was studied by means of experimental infections of Subulina octona, and it was completed 40 days post-infection, with encystment of the metacercaria. The morphology of the larval stages and the site of infection in the snail host were documented through of photomicrography. KEY WORDS. Larval stages; digenetic trematode; snail host.
\end{abstract}

RESUMO. O desenvolvimento larval de Paratanaisia bragai foi estudado através de infecções experimentais em Subulina octona e se completou aos 40 dias pós-infecção, com o encistamento da metacercária. A localização e morfologia dos estágios larvais foram documentadas através de fotomicrografias.

PALAVRAS-CHAVE. Estágios larvais; trematódeo digenético; hospedeiro molusco.

O trematódeo digenético Paratanaisia bragai (Santos, 1934) é encontrado frequentemente em ductos renais de diversas aves domésticas esilvestres (BrRd \& Denton 1950, Freitas 1951, Fedynich et al. 1996). O desenvolvimento larval deste parasito foi estudado pela primeira vez por MALDONADO (1945) utilizando a espécie Subulina octona Bruguière, 1792 como hospedeiro intermediário. Trabal hos mais recentes foram realizados por KelLeR \& AraúJo (1992), com infecções experimentais em Leptinaria unilamellata (D'Orbigny, 1835) e por Brandolinı et al. (1997) com S. octona. Estes últimos autores verificaram sob condições experimentais a influência do parasitismo sobre a função reprodutiva, taxa de crescimento, concentração de cálcio nas conchas e consumo de oxigênio pelos moluscos infectados. As espécies L. unilamellata e S. octona pertencem à família Subulinidae, apresentam-se amplamente distribuídas pelo território brasileiro e são encontradas em locais úmidos e sombreados, como jardins (Araújo \& BESSA 1993). Este estudo teve por objetivos: acompanhar histologicamente e documentar através de fotomicrografias o desenvolvimento larval de P. bragai em S. octona.

\section{MATERIAL E METÓDOS}

Pombos adultos da espécie Columba livia Gmelin, proce dentes do bairro Campo Lindo, município de Seropédica, Rio de Janeiro, foram submetidos a exames de fezes pelo método de sedimentação (DE CARL 1994) para verificação da infecção. Aqueles infectados foram sacrificados e necropsiados confor- me os princípios éticos estabelecidos pela Comissão de Ética em Pesquisa e Experimentação em Biologia, Universidade Federal Rural do Rio de Janeiro.

Os hel mintos foram coletados dos ductos renais dos pombos e transferidos para placas de petri contendo solução salina fisiológica 0,85\%, onde foram mantidos por 24 horas à temperatura ambiente para a liberação de ovos. Como o número de ovos liberados, espontaneamente, foi pequeno, alguns espécimes do parasito foram dilacerados para a obtenção de um maior número de ovos.

Foram utilizados 50 espécimes de S. octona nascidos no laboratório e divididos em cinco grupos, com o tamanho da concha variando entre 4 e $6 \mathrm{~mm}$ de comprimento para as infecções experimentais. As infecções foram feitas em placas de petri de tamanho médio, forradas com papel filtro umedecido com água. Os ovos de P. bragai foram pipetados sobre pedaços de folhas de repolho, sendo estimada uma média de cinco ovos por molusco e o tempo de contato com ovos foi de seis horas. Terminado o tempo de contato com os ovos, os moluscos eram transferidos para recipientes de vidro maiores, forrados com papel filtro umedecido com água. A manutenção dos moluscos foi feita diariamente. Durante todo o experimento, os moluscos receberam alimentação exclusivamente vegetal composta de alface, cenoura, repolho e pepino "in natura".

Os moluscos foram dissecados, periodicamente, sendo a massa visceral retirada do interior da concha e transferida para 

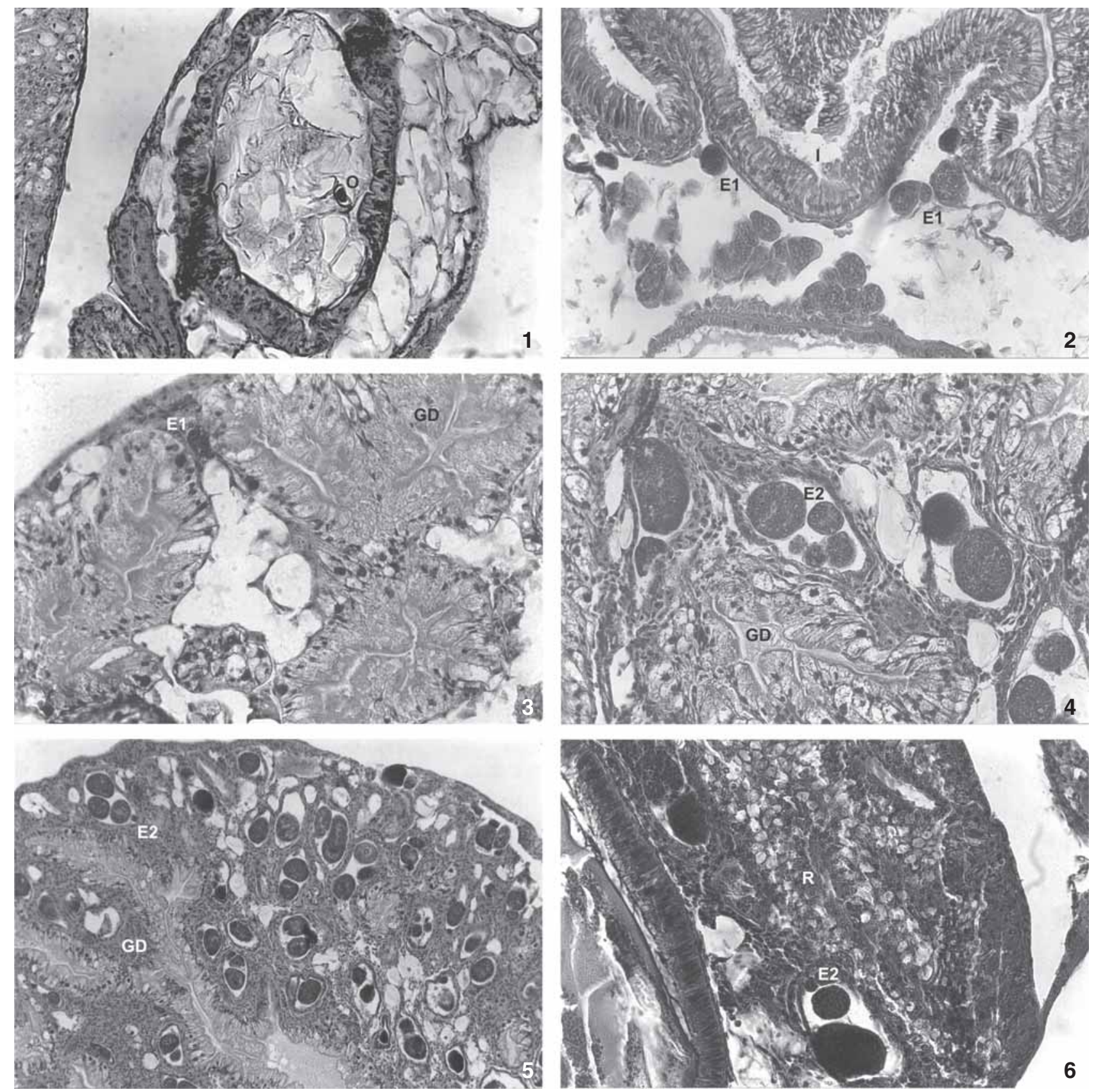

Figuras 1-6. Desenvolvimento larval de Paratanaisia bragai em Subulina octona. (1) Região anterior do trato digestivo do molusco, mostrando um ovo do parasito uma hora após a infecção; (2) esporocistos de primeira geração ( $\left.E_{1}\right)$ aderidos à parede do intestino (I) do molusco com seis dias de infecção; (3) esporocisto de primeira geração entre os ácinos da glândula digestiva (GD) do molusco com oito dias de infecção; (4) esporocistos de segunda geração $\left(E_{2}\right)$ espalhados pela glândula digestiva do molusco com 15 dias de infecção; (5) esporocistos de segunda geração na glândula digestiva do molusco com 20 dias de infecção; (6) esporocistos de segunda geração no rim (R) do molusco com 25 dias de infecção.

o fixador Dubosq-Brasil modificado (etanol $80^{\circ} \mathrm{GL}, 600 \mathrm{ml}$; ácido acético glacial, $150 \mathrm{ml}$ e formalina comercial, $250 \mathrm{ml}$ ) por 12 horas. Seguindo-se o processamento histológico e a coloração por hematoxilina-eosina (BAnCROFt \& Stevens 1996).

Revista Brasileira de Zoologia 23 (4): 1097-1100, dezembro 2006 


\section{RESULTADOS E DISCUSSÃO}

Keller \& Araújo (1992) utilizaram diferentes espécies de moluscos para as infecções experimentais a partir de fezes e excretas renais de Gallus gallus $L$. natural mente infectados com P. bragai, e obtiveram sucesso apenas na infecção de L. unilamellata. BRANDOLINI et al. (1997) infectaram experimentalmente espécimes de S. octona e L. unilamellata, utilizando exclusivamente ovos de P. bragai. A metodologia de infecção utilizada no presente estudo assegurou que os moluscos fossem infectados apenas com ovos de P. bragai, já no trabalho de Keller \& Araújo (1992) não havia certeza sobre a presença, ou não, de outra espécie de helminto, o que pode ter desencadeado uma reação antagônica entre os parasitos, influenciando nos resultados obtidos por estes autores. Em 50 espécimes de S. octona expostos ao contato com os ovos de P. bragai, no presente estudo, 43 (86\%) espécimes adquiriram a infecção permitindo o completo desenvolvimento do parasito até o estágio de metacercária.

O desenvolvimento Iarval de P. bragai foi documentado através de fotomicrografias de cortes histológicos de espécimes deS. octona infectados experimentalmente. Um ovo de P. bragai foi observado na porção anterior do trato digestivo de um molusco fixado após uma hora do contato inicial com os ovos (Fig. 1). Nas dissecações dos moluscos realizadas, respectivamente, aos seis, oito e dez dias após infecção, foram observados vários esporocistos de primeira geração, com a forma de uma massa arredondada de células germinativas, com núcleos que se coravam intensamente. Esses esporocistos inicialmente se localizavam junto à parede do intestino e, à medida que evoluíam, espalhavam-se entre os ácinos da glândula digestiva (Figs 2 e 3). Esporocistos de segunda geração em diferentes estágios de desenvolvimento foram observados na glândula digestiva de um molusco fixado aos 15 dias pós-infecção (Fig. 4). Um grande número de esporocistos de segunda geração foi observado entre os ácinos da glândula digestiva do molusco, aos 20 dias após a infecção (Fig. 5). Esporocistos de segunda geração também foram observados no rim de um molusco, aos 25 dias após a infecção (Fig. 6). Aos 32 dias pós-infecção foi observada uma cercária completamente formada, em meio a bolas germinativas ainda não diferenciadas (Fig. 7). A cercária com corpo alongado e afunilado posteriormente, apresentava o acetábulo desenvolvido no terço médio do corpo. Foi possível verificar em lâminas preparadas após as dissecações dos moluscos, que as cercárias apresentavam movimentação bastante lenta, no interior do esporocisto de segunda geração, porém, quando liberadas, esse movimento tornava-se mais rápido e vigoroso, embora que por pouco tempo.

De acordo com MALDONADO (1945) a capacidade germinativa do esporocisto de primeira geração depende em grande parte da disponibilidade de espaço dentro do hospedeiro, e esse processo pode durar até dois meses. Esse autor observou uma cauda rudimentar, representada por um pequeno botão em algumas cercárias e em outras a extremidade posterior do corpo

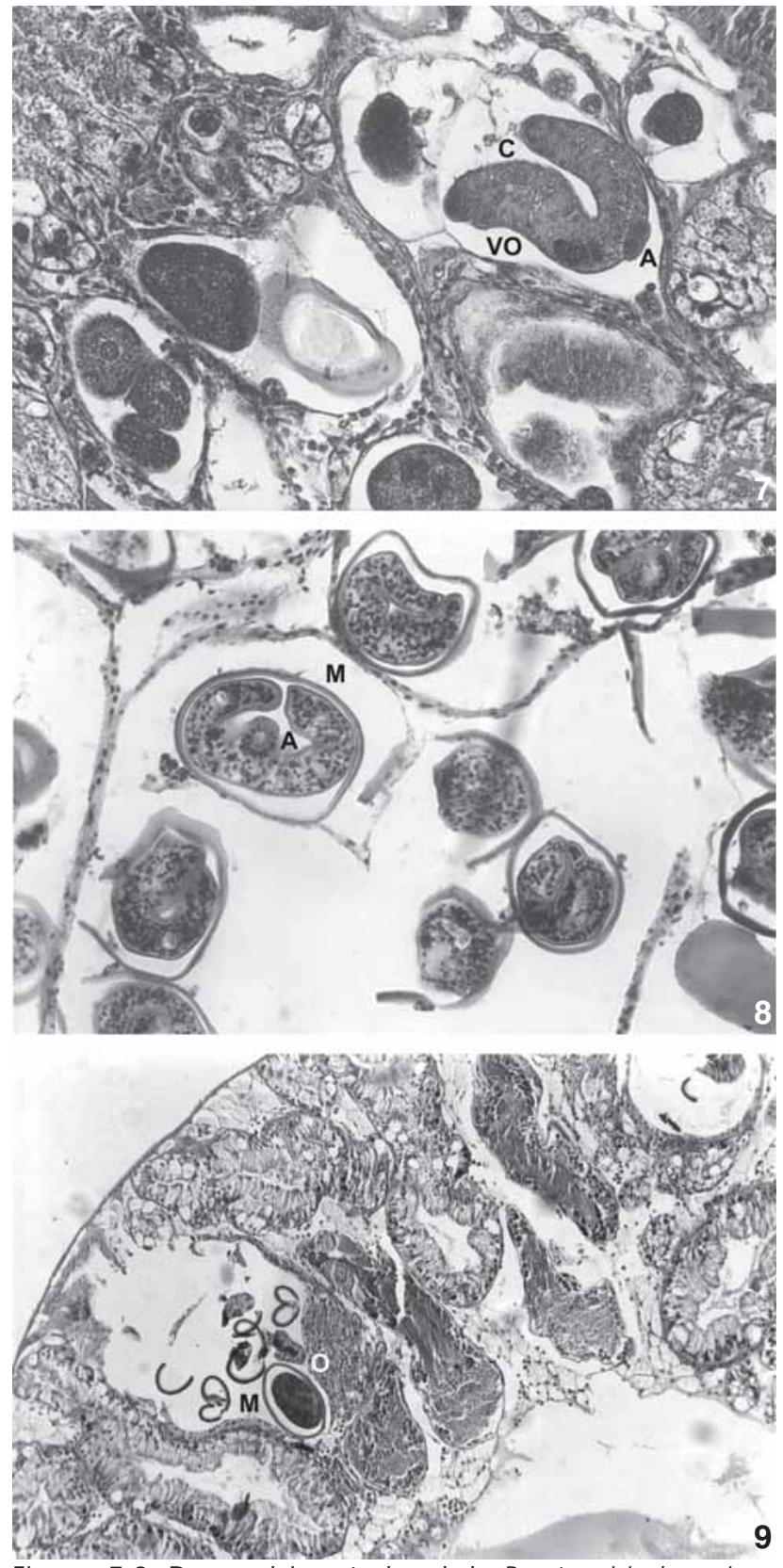

Figuras 7-9. Desenvolvimento larval de Paratanaisia bragai em Subulina octona. (7) Cercária (C) na glândula digestiva do molusco com 32 dias de infecção, ventosa oral (VO) e acetábulo (A); (8) metacercária (M) causando acentuada destruição dos ácinos da glândula digestiva do molusco após 40 dias de infecção; (9) ação mecânica da metacercária sobre o ovotestis (O) do molusco com 40 dias de infecção.

se apresentava contorcida, dando a fal sa impressão de uma cauda rudimentar. Nas cercárias observadas, no presente estudo, não se verificou a presença de nenhum botão ou modificação

Revista Brasileira de Zoologia 23 (4): 1097-1100, dezembro 2006 
da extremidade posterior do corpo que pudessem ser interpretados como uma cauda. MaldonAdo \& Hoffman (1941) e M ALdoNADO (1945) registraram a presença do acetábulo na cercária e em espécimes jovens. Segundo esses autores, com o desenvolvimento do adulto, o acetábulo crescia ligeiramente, mas eventualmente atrofiava, não sendo observado na maturidade sexual do parasito. O que está em parte de acordo com os resultados obtidos no presente estudo, quando se verificou a presença do acetábulo na cercária e metacercária.

A primeira metacercária foi observada em um molusco com 32 dias de infecção. A metacercária de P. bragai, de formato ovalado, apresentava um cisto bastante resistente, que não se rompia facilmente, mesmo sob forte compressão, mostrando movimentação por mais de 24 horas após serem retiradas do molusco e mantidas em solução salina fisiológica a $0,65 \%$, no refrigerador. A partir do 40 으 dia após a infecção, alguns moluscos apresentavam a glândula digestiva bastante comprometida devido à compressão exercida pelas metacercárias (Fig. 8).

Em cortes histológicos de um molusco dissecado após 40 dias da infecção foi possível verificar a ação mecânica de metacercárias sobre o ovotestis do molusco (Fig. 9). BRANDolinı et al. (1997), verificaram uma redução no número de ovos por postura e aumento no intervalo de realização de posturas por espécimes de S. octona infectados experimentalmente com $\mathrm{P}$. bragai. Esses autores caracterizaram a influência do parasito sobre o processo reprodutivo do molusco como uma castração parasitária do tipo indireto e nutricional, por não terem observado nenhuma metacercária com ação direta sobre a gônada do molusco. Contudo, a ação mecânica sobre os tecidos gonadais observada no presente estudo evidenciou um processo de castração parasitária direta. Alterações histopatológicas em diferentes níveis foram observadas nos moluscos infectados, ao longo do período de infecção, culminando com a formação das metacercárias. Pode ser evidenciada uma acentuada destruição dos ácinos da glândula digestiva, rim e ovotestis de $\mathrm{S}$. octona que ocasionou uma debilidade generalizada no organismo do molusco.

Recebido em 31.III.2006; aceito em 27.X.2006.

\section{REFERÊNCIAS BIBLIOGRÁFICAS}

Araújo, J.L. de B. \& E.C. DE A. Bessa. 1993. Moluscos de importância econômica no Brasil. Il. Subulinidae, Subulina octona (Bruguiére) (Mollusca, Gastropoda, Pulmonata, Stylommatophora). Revista Brasileira de Zoologia, Curitiba, 10 (3): 489-497.

Bancroft, J.D. \& A. Stevens. 1996. Theory and Practice of Histological Techniques. New York, Churchill Livingstone, 766p.

Brandolini, S.V.P.B.; S.B. Amato \& A. De A. Pereira. 1997. Relacionamento de Tanaisia bragai (Digenea, Eucotylidae) e seu hospedeiro intermediário, Subulina octona (Gastropoda, Subulinidae) sob condições experimentais. Parasitologia al Día, Santiago, 21: 109-113.

Byrd, E.E. \& J.F. Denton. 1950. The helminth parasites of birds. I. A review of the trematode genus Tanaisia Skrjabin, 1924. American Midland Naturalist, Notre Dame, 43 (1): 32-57.

DE CARLI, G.A. 1994. Diagnóstico laboratorial das parasitoses humanas. Métodos e técnicas. Rio de Janeiro, MEDSI Editora Médica e Científica, 315p.

Fedynich, A.M.; D.B. Pence \& J.F. Bergan. 1996. Helminth community structure and pattern in sympatric populations of black-bellied and fulvous whistling ducks. Canadian Journal of Zoology, Ottawa, 74: 2219-2225.

FreitAS, J.F.T. DE. 1951. Revisão da família Eucotylidae Skrjabin, 1924 (Trematoda). Memórias do Instituto Oswaldo Cruz, Rio de Janeiro, 49: 33-123.

Keller, D.G. \& J.L. de B. Araújo. 1992. Ciclo evolutivo de Paratanaisia bragai (Santos, 1934) (Trematoda, Eucotylidae) com novo hospedeiro intermediário no Brasil: Leptinaria unilamellata (D'Orbigny, 1835) (Gastropoda, Pulmonata, Subulinidae) em condições de laboratório. Revista Brasileira de Parasitologia Veterinária, São Paulo, 1 (2): 89-92.

Maldonado, J.F. 1945. The life cycle of Tamerlania bragai Santos, 1934 (Eucotylidae), a kidney fluke of domestic pigeons. Journal of Parasitology, Lawrence, 31: 306-314.

Maldonado, J.F. \& W.A. Hoffman. 1941. Tamerlania bragai, a parasite of pigeons in Puerto Rico. Journal of Parasitology, Lawrence, 27: 91. 